\title{
Structure aggregation of carbon black in ethylene-propylene diene polymer
}

\author{
S. N. Lawandy, S. F. Halim*, N. A. Darwish \\ Laboratory of Metrology and Technology of Polymer, National Institute of Standards (NIS),Tersa St., 12211 Giza, Egypt
}

Received 30 November 2008; accepted in revised form 27 January 2009

\begin{abstract}
The modulus of filled and unfilled Ethylene-propylene diene rubber (EPDM) vulcanizates was used to predict the shape-factor of carbon black aggregation in the polymer. Four types of carbon black that vary in particle size and structure were used in this study. Quadratic curves relating the carbon black volume concentration and the modulus ratio of filled and unfilled rubber vulcanizates were used to adopt the shape factor of certain carbon black type. The shape factor of MT, HAF, SRF and Lampblack were 3, 3.75, 4 and 4.25 respectively. X-ray diffraction technique (XRD) was also used to evaluate the relative size of crystallite on the filler surface to that of the rubber and correlating it to the shape factor of carbon black aggregation in the polymer. Effect of the $\mathrm{pH}$ values and structure of carbon blacks used on the shape factor of filler aggregates were also studied. It was found that the shape factor is independent on the particle size while it is dependent on the $\mathrm{pH}$ value and structure of carbon black. Also the crystallites size of the filler is proportional to the shape factor.
\end{abstract}

Keywords: rubber, EPDM, carbon black, shape factor, vulcanizates

\section{Introduction}

The polymer-carbon black filler reinforcement depends widely on the polymer type, carbon black type and structure. Another factor affecting this reinforcement is the filler-filler interaction which leads to the formation of three dimensional aggregation structures within the bulk of the rubber matrix. These aggregations take various shapes which may be spherical or ellipsoidal with different major and minor axes [1]. Several aggregates connect through Van der Waals forces to give weak, giant assembled called agglomerates [2-4]. Several authors investigated and discussed the structure of these aggregates by using several techniques such as relating the modulus of unfilled rubber to that of filled rubber [5, 6], scanning electron microscope $[7,8]$ and Transmission electron microscopy TEM [9].
In this paper we will discuss the shape factor of the filler aggregates in the rubber matrix starting by the enhancement of elastomer modulus based on the rubber-filler interaction. These modulus studies started by Rehner [10] who adopted the wellknown Einstein equation (Equation (1)):

$\eta=\eta_{0}(1+2.5 C)$

where $\eta$ and $\eta_{0}$ are the viscosities of liquid having suspended particles and that of the liquid respectively and $C$ is the volume fraction of the particles suspended in the liquid. Smallwood, who suggested a rubber-filler interaction [11], replaced the viscosity terms in Equation (1) by Youngs modulus terms to be Equation (2):

$$
E_{f}=E_{0}(1+2.5 C)
$$


where $E_{f}$ and $E_{0}$ in Equation (2) are the moduli of filled and unfilled vulcaniztes respectively and $C$ is the volume fraction of the filler in the mix. Equation (2) can be hold only for low concentration of filler. Guth [12] gives a modified equation (Equation (3)):

$$
E_{f}=E_{0}\left(1+2.5 C+14.1 C^{2}\right)
$$

where the last term of Equation (3) is due to the interaction between carbon particulates and the polymer. However, these last two equations have been shown to hold for large particle size of carbon black where the rubber-filler interaction is comparatively small. For non spherical particles Guth [13] introduce shape factor $f_{s}$, which is the ratio of asymmetric particles length to their diameter, and proposed the Equation (4):

$$
E_{f}=E_{0}\left(1+0.67 f_{s} C+1.62 f_{s}^{2} C^{2}\right)
$$

For higher volume fraction of filler, several equations have been given $[14,15]$. Recently Oberdisse et al. $[16,17]$ studied the reinforcement effect of soft polymer which is nanolatex polymer polymethyl methacrylate and polybutylacrylate by nanosilica. They study the structure of the silica in the composite matrix by small angle neutron scatterings (SANS) and stress-strain measurements. In order to analyses their stress-strain data they use other expression for modulus. This expression was given by Oberdisse as shown in Equation (5):

$$
\frac{E}{E_{\text {latex }}}=\frac{\exp 2.5 C_{a g g}}{1-\frac{C_{a g g}}{{ }^{\max } C_{a g g}}}
$$

where (Equation (6)):

$$
C_{a g g}=\frac{C_{s i}}{v}
$$

where $C_{s i}$ is in Equation (6) the volume fraction of silica, ${ }^{\max } C_{\text {agg }}$ is the volume fraction aggregation at higher volume concentration $60 \%$ and $v$ is the aggregate compactly factor. The experimental determination of $v$ is not an easy task and that there are a lot of arguments about ${ }^{\max } C_{\text {agg }}$ because of collisions between aggregates and the dispersion of aggregation. Similar trials for the filler aggregation and structure were indicated by Medalia [18-19].

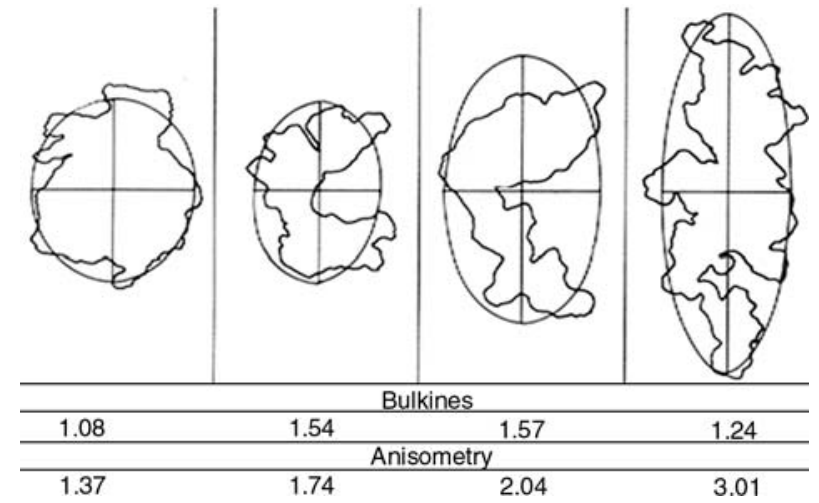

Figure 1. Aggregation structure of carbon black [18, 19]

His technique depends on the analysis of electron micrographs. The filler aggregate shape was subjected to computer integrations. The maximum and minimum moments of inertia were determined. These were the two axes of an ellipse. The ratio between these axes is the anisometry $Q$. The ratio between silhouette area over the ellipse area is the bulkiness, $B$, from which the structure factor $T=Q B-1$. Figure 1 shows an illustration for the different anisometry $(Q)$ of filler aggregates.

The trouble with calculating the structure factor is that many aggregates or particles have to be reviewed before average value for anisometry and bulkiness can be reached and hence the measurement is very consuming. Later, transmission electron microscopy combined with computerized tomography was used by Kohjiya et al. [9] and others to display the skeleton characteristics of nanofiller carbon black network in natural rubber. Their study was based on the fact that filler-filler interaction is higher than filler to rubber and that further association of filler aggregates, i.e. agglomeration leads to another form of filler network [20]. Figure 2 shows the aggregation and agglomeration of carbon black in the rubber.

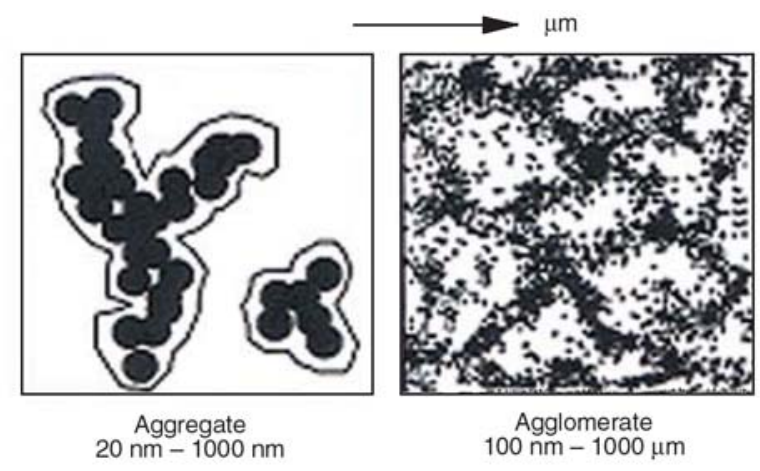

Figure 2. The aggregation and agglomeration of carbon black in rubber [9] 
The techniques mentioned before to display the filler aggregation, agglomeration and the method used to quantify the filler network showed controversial results.

We used the simple stress-strain data to reach certain reliable data explaining the shape-factor of carbon black in a certain polymer matrix. We verify our results by X-ray diffraction technique (XRD).

\section{Experimental}

\subsection{Materials}

The polymer used in this study is Ethylene-propylene diene rubber (EPDM), Buna EPT 9650, Bayer. The Ethylene content is $53 \pm 4$, ENB content $6.5 \pm 1.1$ and the viscosity $\mathrm{ML}(1+8)$ at $150^{\circ} \mathrm{C}$ is $60 \pm 6$. Dicumyl peroxide (DCP), UN Korean of density 1.56 was used as cross-linking agent. High abrasion carbon black HAF-LS (N-326), Thermal black MT (N-990), Semi-reinforcing SRF (N-774) and Lampblack were used as fillers with different concentrations in the rubber mixes. The main structural parameters of carbon blacks are listed in Table 1. The mix formulations are given in Table 2.

\subsection{Mixing and sample preparation}

Mixing was carried out on two-roll laboratory open mixing mill $(152.4 \times 330.2 \mathrm{~mm})$ at a friction ratio 1:1.4. The mixing was carried out according to ASTM D3182.89. The optimum cure time of each compounded rubber mix was detected using a Monsanto Rheometer (Alpha Technologies MDR 2000) working at $162^{\circ} \mathrm{C}$. An average cure time for all mixes was selected and used for all samples to ensure fair results. Samples for testing were compression molded in a laboratory hydraulic press (Mackey Bowley, $\mathrm{C} 1136199$ ) at $162^{\circ} \mathrm{C}$. The rheometric properties of each mix are given in Table 3.

\subsection{Stress-strain measurements}

Dumbbell shape samples prepared according to ASTM D 412-98a were used for relaxed stressstrain measurements. Zwick tensile testing machine Z010/TH2A was run at speed $10 \mathrm{~mm} / \mathrm{min}$ and the stress-strain curves of various mixes was recorded up to $16 \%$ strain.

Table 1. Formulation of the EPDM mixes containing various types of carbon blacks

\begin{tabular}{|c|c|c|c|c|c|c|c|c|c|c|c|}
\hline \multicolumn{12}{|c|}{ Formulation of the EPDM mixes containing HAF and SRF carbon blacks } \\
\hline $\begin{array}{c}\text { Mixes no. } \\
\text { Ingredients [phr] }\end{array}$ & B & $\mathbf{H}_{\mathbf{1}}$ & $\mathbf{H}_{2}$ & $\mathbf{H}_{3}$ & $\mathbf{H}_{4}$ & $\mathbf{H}_{5}$ & $\mathbf{S}_{1}$ & $\mathbf{S}_{2}$ & $\mathbf{S}_{3}$ & $\mathbf{S}_{4}$ & $\mathbf{S}_{\mathbf{5}}$ \\
\hline EPDM & 0 & 100 & 100 & 100 & 100 & 100 & 100 & 100 & 100 & 100 & 100 \\
\hline Stearic Acid & 2 & 2 & 2 & 2 & 2 & 2 & 2 & 2 & 2 & 2 & 2 \\
\hline Zinc oxide & 5 & 5 & 5 & 5 & 5 & 5 & 5 & 5 & 5 & 5 & 5 \\
\hline Dicumyl peroxide & 3 & 3 & 3 & 3 & 3 & 3 & 3 & 3 & 3 & 3 & 3 \\
\hline HAF & - & 20 & 30 & 40 & 50 & 60 & - & - & - & - & - \\
\hline SRF & - & - & - & - & - & - & 20 & 30 & 40 & 50 & 60 \\
\hline \multicolumn{12}{|c|}{ Formulation of the EPDM mixes containing MT and Lampblack carbon blacks } \\
\hline $\begin{array}{c}\text { Mixes no. } \\
\text { Ingredients [phr] }\end{array}$ & B & $\mathbf{M}_{1}$ & $\mathbf{M}_{2}$ & $\mathbf{M}_{3}$ & $\mathbf{M}_{4}$ & $\mathbf{M}_{5}$ & $\mathbf{L}_{1}$ & $\mathbf{L}_{2}$ & $\mathbf{L}_{3}$ & $\mathbf{L}_{4}$ & $\mathbf{L}_{5}$ \\
\hline EPDM & 0 & 100 & 100 & 100 & 100 & 100 & 100 & 100 & 100 & 100 & 100 \\
\hline Stearic Acid & 2 & 2 & 2 & 2 & 2 & 2 & 2 & 2 & 2 & 2 & 2 \\
\hline Zinc oxide & 5 & 5 & 5 & 5 & 5 & 5 & 5 & 5 & 5 & 5 & 5 \\
\hline Dicumyl peroxide & 3 & 3 & 3 & 3 & 3 & 3 & 3 & 3 & 3 & 3 & 3 \\
\hline MT & - & 20 & 30 & 40 & 50 & 60 & - & - & - & - & - \\
\hline Lampblack & - & - & - & - & - & - & 20 & 30 & 40 & 50 & 60 \\
\hline
\end{tabular}

Table 2. The main specifications of the carbon blacks used [1]

\begin{tabular}{|l|c|c|c|}
\hline \multicolumn{1}{|c|}{ Carbon black } & $\begin{array}{c}\text { Average (elementary) particle size }{ }^{\mathbf{1}} \\
\text { [nm] }\end{array}$ & pH value & $\begin{array}{c}\text { Structure }^{\mathbf{2}} \\
\text { [cm }^{\mathbf{2}} \mathbf{\text { DBP/100 }} \text { g filler] }\end{array}$ \\
\hline HAF (N-326) & $26-30$ & 9.2 & 67 \\
\hline SRF (N-774) & $61-100$ & 9.9 & 70 \\
\hline MT (N-990) & $201-500$ & 7.4 & 33 \\
\hline
\end{tabular}

${ }^{1}$ According to the ASTM D1765-86

${ }^{2}$ According to the ASTM D2414 
Table 3. Rheological and mechanical properties of filled and unfilled EPDM rubber vulcanizates

\begin{tabular}{|c|c|c|c|c|c|c|c|c|c|c|c|}
\hline \multicolumn{12}{|c|}{ Rheological and mechanical properties of EPDM rubber vulcanizates containing HAF and SRF carbon blacks } \\
\hline $\begin{array}{l}\text { Mixes } \\
\text { Curing characteristics }\end{array}$ & B & $\mathbf{H}_{1}$ & $\mathbf{H}_{2}$ & $\mathbf{H}_{3}$ & $\mathbf{H}_{4}$ & $\mathbf{H}_{5}$ & $\mathbf{S}_{1}$ & $\mathbf{S}_{2}$ & $\mathbf{S}_{\mathbf{3}}$ & $\mathbf{S}_{4}$ & $\mathbf{S}_{5}$ \\
\hline Minimum Torque $[\mathrm{N} \cdot \mathrm{mm}]$ & 0.01 & 0.02 & 0.02 & 0.2 & 0.03 & 0.03 & 0.02 & 0.02 & 0.02 & 0.02 & 0.03 \\
\hline Maximum Torque $[\mathrm{N} \cdot \mathrm{mm}]$ & 0.15 & 0.19 & 0.21 & 0.25 & 0.29 & 0.32 & 0.20 & 0.22 & 0.25 & 0.30 & 0.31 \\
\hline Cure time, $\mathrm{t}_{\mathrm{C} 90}[\mathrm{~min}]$ & 13.0 & 13.3 & 13.5 & 13.50 & 13.4 & 11.9 & 11.3 & 11.20 & 11.10 & 11.30 & 11.3 \\
\hline Scorch time ts2 [min] & 0.90 & 0.94 & 0.89 & 0.82 & 0.77 & 0.70 & 0.84 & 0.81 & 0.76 & 0.68 & 0.68 \\
\hline Tensile Strength [MPa] & 1.41 & 3.97 & 6.36 & 7.55 & 9.42 & 14.4 & 5.22 & 9.06 & 14.1 & 16.8 & 19.9 \\
\hline Elongation at break [\%] & 140 & 241 & 427 & 346 & 326 & 364 & 358 & 429 & 451 & 403 & 392 \\
\hline \multicolumn{12}{|c|}{ Rheological and mechanical properties of EPDM rubber vulcanizates containing MT and Lampblack carbon blacks } \\
\hline $\begin{array}{l}\text { Mixes } \\
\text { Curing characteristics }\end{array}$ & B & $\mathbf{M}_{1}$ & $\mathbf{M}_{2}$ & $\mathbf{M}_{3}$ & $\mathbf{M}_{4}$ & M5 & $\mathbf{L}_{1}$ & $\mathbf{L}_{2}$ & $\mathbf{L}_{3}$ & $\mathbf{L}_{4}$ & $\mathbf{L}_{5}$ \\
\hline Minimum Torque $[\mathrm{N} \cdot \mathrm{mm}]$ & 0.01 & 0.02 & 0.02 & 0.02 & 0.02 & 0.02 & 0.02 & 0.02 & 0.02 & 0.03 & 0.03 \\
\hline Maximum Torque $[\mathrm{N} \cdot \mathrm{mm}]$ & 0.15 & 0.20 & 0.30 & 0.24 & 0.26 & 0.28 & 0.22 & 0.26 & 0.27 & 0.33 & 0.35 \\
\hline Cure time, $\mathrm{t}_{\mathrm{C} 90}[\mathrm{~min}]$ & 13.0 & 11.4 & 11.3 & 11.2 & 11.2 & 11.3 & 11.4 & 11.3 & 11.3 & 11.1 & 11.2 \\
\hline Scorch time ts2 [min] & 0.90 & 0.81 & 0.76 & 0.70 & 0.68 & 0.66 & 0.73 & 0.67 & 0.67 & 0.58 & 0.55 \\
\hline Tensile Strength [MPa] & 1.41 & 3.52 & 3.45 & 5.9 & 7.32 & 9.1 & 4.5 & 8.0 & 10.7 & 15.9 & 15.5 \\
\hline Elongation at break [\%] & 140 & 313 & 261 & 353 & 338 & 378 & 314 & 347 & 352 & 389 & 336 \\
\hline
\end{tabular}

\subsection{X-ray diffraction (XRD)}

Philips Analytical X-ray diffraction, type PW1840 of $\mathrm{Cu}$ radiation was used. It operates at $40 \mathrm{kV}$ and $30 \mathrm{~mA}$ with a wavelength $(\lambda) 1.54056 \AA$. The diffractograms were recorded continuously in the range $2 \theta=4-70^{\circ}$.

\section{Results and discussion:}

\subsection{Determination of shape factor from stress-strain measurements}

The modulus at $16 \%$ strain values of the unfilled EPDM rubber vulcanizates $\left(E_{0}\right)$ and those of filled $\left(E_{f}\right)$, at the various carbon black concentrations 20 , $30,40,50$ and $60 \mathrm{phr}$ was measured and the ratio $E f / E_{0}$ were calculated. Also the carbon black volume fraction $(C)$ was calculated for each concentration (carbon black volume/rubber filled volume). Quadratic curves of carbon black shape-factor were plotted using Equation (4) by implementing several values of $f_{s}(2.5,3,3.5,4$ and 4.5). By plotting curves using the values of the ratio $E_{f} / E_{0}$ versus $C$ for each carbon black type, the shape-factor of each carbon black can be adduced by selecting the quadratic shape-factor curve to which the points are fitted. Figure 3 shows these quadratic curves and that of EPDM filled rubber with MT, HAF, SRF and LB. It was found that the shape factor of Lampblack, SRF, HAF and MT are 4.25, 4, and 3.75, 3 respectively. These recorded results show that the

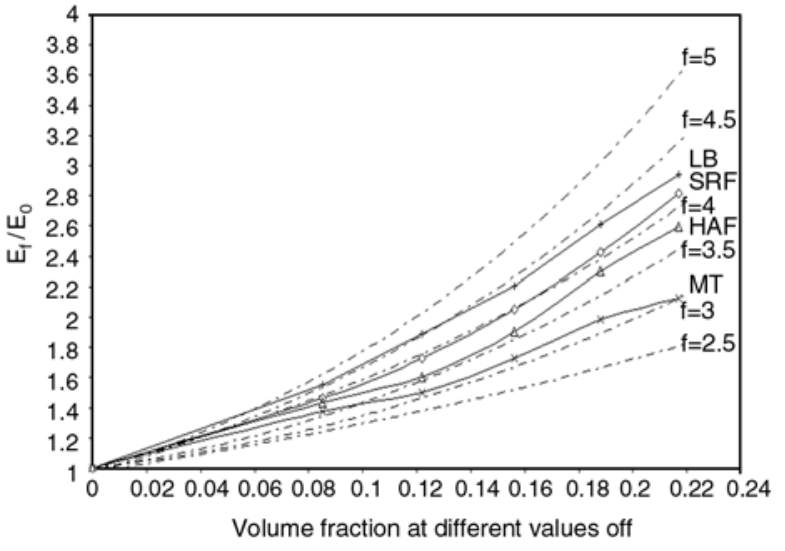

Figure 3. Shape factor of different carbon blacks aggregates

shape factor is independent of the particle size of the carbon black that is given in Table 1 .

\subsection{Shape factor and $\mathrm{pH}$ value and structure of carbon black}

Table 2 includes two important parameters which are the structure and $\mathrm{pH}$ value of these blacks. It is to be noted here that, the Lampblack $\mathrm{pH}$ value is not mentioned in this table because of the wide range and classifications of these blacks. However, plotting the relation between the shape factor and $\mathrm{pH}$ values of the used carbon black, the $\mathrm{pH}$ value of the used LB black was estimated to be nearly 10.3. This can be shown in Figure 4. It is clear from Figure 4 that the shape factor increases as the $\mathrm{pH}$ val- 


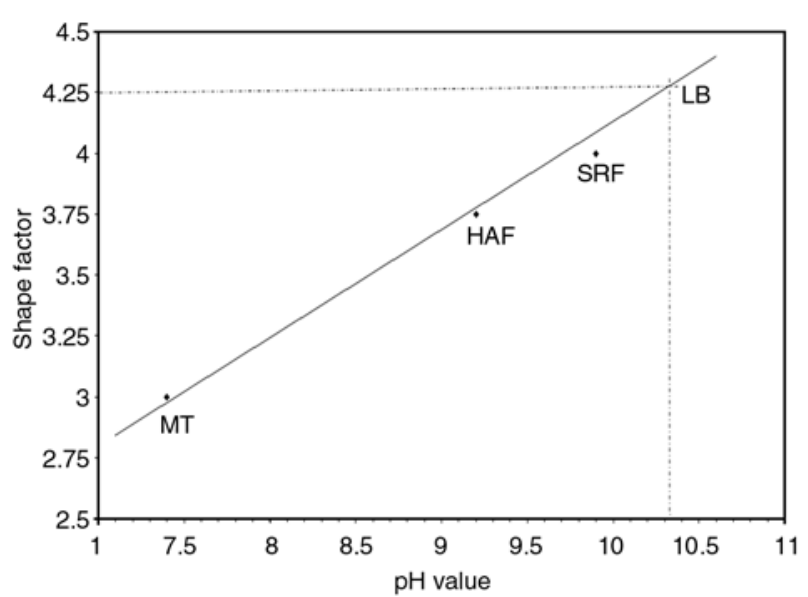

Figure 4. The relation between $\mathrm{pH}$ values of carbon blacks and the shape factor of carbon black aggregates

ues of carbon black increases. This is referred to the presence of chemisorbed oxygen complexes on carbon black surfaces. The major functional oxygenated groups are carboxylic, quinoic phenolic or lactonic groups. Oxygenated functional groups are acidic and control the $\mathrm{pH}$ value of carbon black [21, 22]. The $\mathrm{pH}$ values of carbon black affect their dispersion in the polymer matrix [23].

Plotting a relation between carbon black structure and the aggregates shape factor of carbon blacks reveals an interesting relation as shown in Figure 5. This relation was expected as the carbon black structure is a sort of volume concentration of carbon in one $\mathrm{cm}^{3}$ of filler. Carbon black structure is determined by Dibutyl Phthalate (DBP) absorption (ASTM D2414) which measures the amount of oil that can be absorbed by the filler particles. A high value of DBP absorption indicates a high-structure black $[22,24,25]$. A high structure black has a

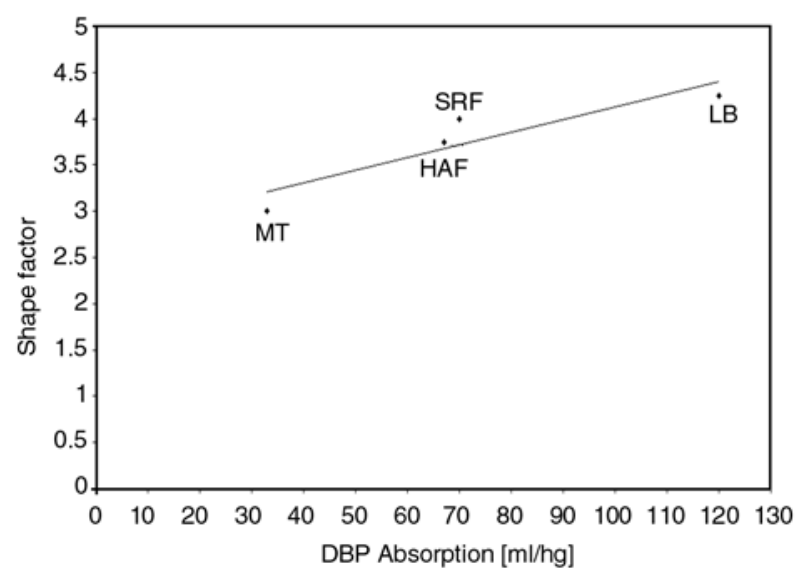

Figure 5. The relation between DBP values(Structure) of carbon blacks and the shape factor of carbon black aggregates strong attractive force between its aggregate and tends to produce larger aggregates in contact separated by small distances [26-28]. It was reported [26] that the aggregate anisometry is associated with the DBP absorption capacity. Figure 5 shows that the higher structure of carbon black are the higher the shape factor of carbon black aggregates.

\subsection{XRD}

In order to investigate the degree of aggregation of carbon black in the EPDM rubber vulcanizates; attempts were made to quantify the crystalline regions present in EPDM filled with various types of carbon black using X-ray diffraction technique. As shown from Figure 6 all samples showed the same broad pattern at $2 \theta=14-20^{\circ}$ which represent the amorphous EPDM polymer; this is followed by a distinct crystalline region representing the carbon black aggregation at $2 \theta=20-28^{\circ}$. This is expected since carbon black aggregates tend to concentrate in amorphous regions [29]. The width of this carbon black crystalline pattern depends widely on the type of carbon black in the mix. The half-band width of the crystalline pattern that accompanied the amorphous pattern of the rubber was measured accurately (relative to fixed width of the amorphous rubber pattern). These values were plotted versus carbon black shape factor, found before in section 3.1. These can be shown in Figure 7. It is clear that the aggregates shape factor increases with the increase of the half-band width of X-ray patterns which means that the crystallite size decreases (inverse relation) [30, 31]. In other words as the crystallites size decrease the shape factor increases. These results can be correlated with that obtained by Biscoe and Warren [32] who identified the aggregate structure as intermediate between crystalline and amorphous materials. Energy of interaction between polymer and carbon black depends on nature and amount of crystallites. The most energetic sites, which very effectively adsorb polymers, are usually identified as crystallite edges. Small crystallites are not energetically favorable structure [33]. So as the crystallite size decreases the rubber filler interaction decreases this happens in favor to the filler-filler interaction rather than rubber-filler interaction. This is supposed to lead to the formation of aggregates with higher shape factor. 


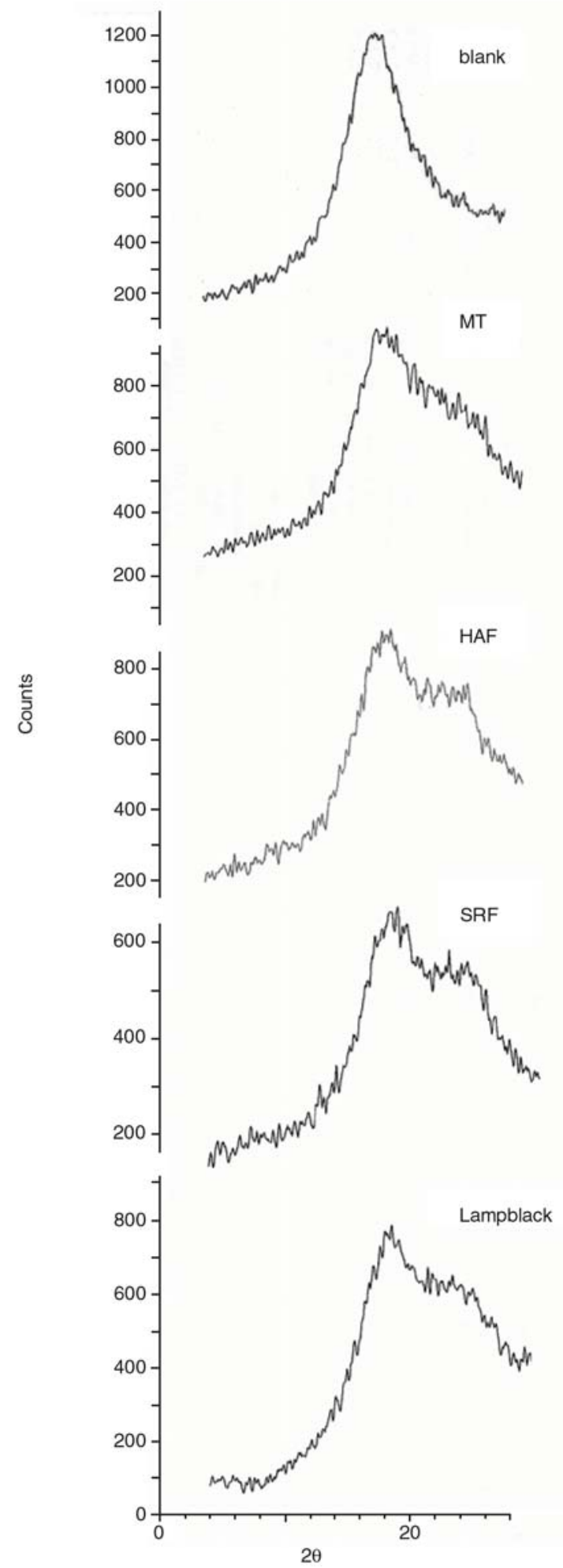

Figure 6. X-ray diffraction patterns for unfilled (blank) and filled EPDM vulcanizates with different fillers

\section{Conclusions}

The modulus at low strain of filled and unfilled rubber is a reliable method to detect the shape factor of

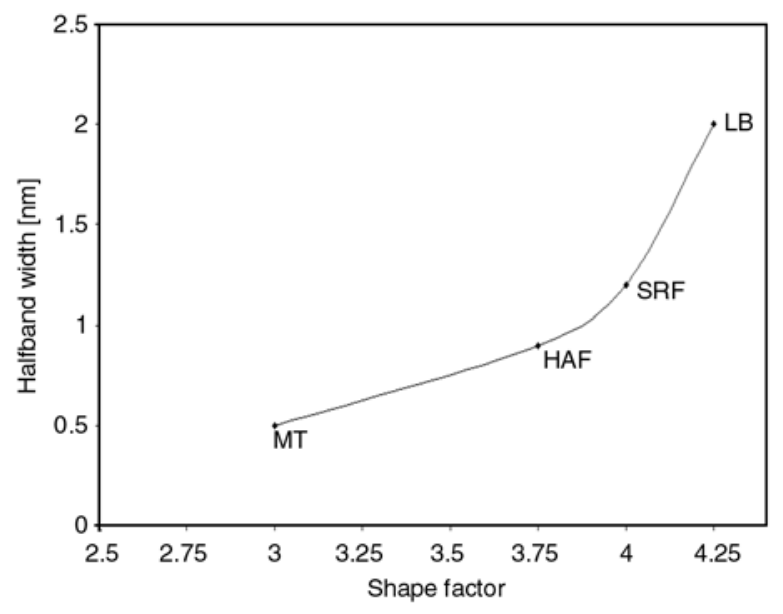

Figure 7. Relative Crystalline region expressed as halfband width of X-ray pattern

different carbon black aggregates in rubber. Also the X-ray diffraction is good tool to estimate the relative distribution of carbon black which can express the degree of aggregation in the rubber mixes. The shape factor of carbon black aggregates in EPDM is independent on the carbon black particle size while it is directly proportional to the $\mathrm{pH}$ value and structure of carbon black.

\section{References}

[1] Leblanc J. L.: Rubber-filler interactions and rheological properties in filled compounds. Progress in Polymer Science, 27, 627-687 (2002). DOI: $10.1016 / \mathrm{S} 0079-6700(01) 00040-5$

[2] Osman M. A., Attallah A.: Interparticle and particlematrix interactions in polyethylene reinforcement and viscoelasticity. Polymer, 46, 9476-9488 (2005). DOI: 10.1016/j.polymer.2005.07.030

[3] Oono R.: Distribution of carbon black in SBR. Journal of Applied Polymer Science, 21, 1743-1749 (2003). DOI: $10.1002 /$ app.1977.070210702

[4] Gruber T., C., Herd C. R.: Anisometry measurements in carbon black aggregate populations. Rubber Chemistry and Technology, 70, 727-746 (2000).

[5] Donnet J-B., Bansal R. C., Wang M-J.: Carbon Black Science and Technology. Marcel Dekker, New York (1993).

[6] Vilgis T. A.: Time scales in the reinforcement of elastomers. Polymer, 46, 4223-4229 (2005). DOI: 10.1016/j.polymer.2005.02.060

[7] Eirich F. R.: Science and technology of rubber. Academic Press, New York (1978).

[8] Zhang A., Wang L., Lin Y., Mi X.: Carbon black filled powdered natural rubber: Preperation, particle size distribution, mechanical properties and structures. Journal of Applied Polymer Science, 101, 1763-1774 (2006).

DOI: 10.1002/app.23516 
[9] Kohjiya S., Katoh A., Suda T., Shimanuki J., Ikeda Y.: Visualization of carbon black networks in rubbery matrix by skeletonisation of 3D TEM image. Polymer, 47, 3298-3301 (2006).

DOI: $10.1016 /$ j.polymer.2006.03.008

[10] Rehner J.: Theory of filler reinforcement in natural and synthetic. The stress in and about particles. Journal of Applied Physics, 14, 638-645 (1943).

DOI: $10.1063 / 1.1714942$

[11] Smallwood H. M.: Limiting law of the reinforcement of rubber. Journal of Applied Physics, 15, 758-766 (1944). DOI: $10.1063 / 1.1707385$

[12] Guth E.: Theory of filler reinforcement. Journal of Applied Physics, 16, 20-25 (1945).

DOI: $\underline{10.1063 / 1.1707495}$

[13] Mullins L., Tobin N. R.: Stress softening in rubber vulcanizates. Part I. Use of a strain amplification factor to describe the elastic behavior of filler-reinforced vulcanized rubber. Journal of Applied Polymer Science, 9, 2993-3009 (1965).

DOI: 10.1002/app.1965.070090906

[14] Ahmed S., Jones F. R.: A review of particulate reinforcement theories for polymer. Journal of Materials Science, 25, 4933-4942 (1990).

DOI: $\underline{10.1007 / \mathrm{BF} 00580110}$

[15] Mooney M.: The viscosity of a concentrated suspension of spherical particles. Journal of Colloid Science, 6, 162-170 (1951). DOI: $10.1016 / 0095-8522(51) 90036-0$

[16] Oberdisse J.: Structure and rheological properties of latex-silica nanocomposites films: Stress-strain isotherms. Macromolecules, 35, 9441-9450 (2002). DOI: $10.1021 / \mathrm{ma} 020635 \mathrm{~d}$

[17] Oberdisse J., El Harrak A., Carrot G., Jestin J., Boué F.: Structure and rheological properties of soft-hard nanocomposites: Influence of aggregation and interfacial modification. Polymer, 46, 6695-6705 (2005). DOI: $10.1016 /$ j.polymer.2005.05.023

[18] Medalia A. I.: Morphology of aggregates. I. Calculations of shape and bulkiness factore; Application to computer-simulated random flocs. Journal of Colloid and Interface Science, 24, 393-404 (1967). DOI: $10.1016 / 0021-9797(67) 90267-6$

[19] Medalia A. I.: Morphology of aggregates. IV. Effective volume of aggregates of carbon black from electron microscopy; Application to vehicle adsorption and to die swell of filled rubber. Journal of Colloid and Interface Science, 32, 115-131 (1970). DOI: $\underline{10.1016 / 0021-9797(70) 90108-6}$

[20] Wolff S., Wang M. J.: Carbon black reinforcement of elastomers. in 'Carbon black' (eds: Donnet J-B., Bansal R. C., Wang M-J.) Marcel Dekker, New York (1993).

[21] Dannenberg E. M.: Carbon-black treadwear ratings from laboratory tests. Rubber Chemistry and Technology, 59, 497-511 (1986).
[22] Huang J-C.: Carbon black filled conducting polymers and polymer blends. Advances in Polymer Technology, 21, 299-313 (2002).

DOI: $10.1002 / \mathrm{adv} .10025$

[23] Dannenberg E. M.: Bound rubber and carbon-black reinforcement. Rubber Chemistry and Technology, 59, 512-524 (1986).

[24] Donnet J., Vidal A.: Carbon black: Surface properties and interactions within elastomers. in 'Advances in polymer science' (eds: Abe A., Albertsson A-C., Duncan R., Dusek K., de Jeu W. H., Kausch H-H., Kobayashi S., Lee K-S., Leibler L., Long T. E., Manners I., Möller M., Nuyken O., Terentjev E. M., Voit B., Wegner G., Wiesner U.) Springer, Berlin, 103-127 (1986).

DOI: $10.1007 / 3-540-15830-8$

[25] Edwards D. C.: Polymer-filler interaction in rubber reinforcement. Journal of Materials Science, 25, 4175-4185 (1990). DOI: $\underline{10.1007 / \mathrm{BF} 00581070}$

[26] Li Z. H., Zhang J., Chen S. J.: Effects of carbon blacks with various structures on vulcanization and reinforcement of filled ethylene-propylene-diene rubber. Express Polymer Letters, 2, 695-704 (2008). DOI: $10.3144 /$ expresspolymlett.2008.83

[27] Donnet J-B.: Fifty years of research and progress on carbon black. Carbon, 32, 1305-1310 (1994). DOI: $\underline{10.1016 / 0008-6223(94) 90116-3}$

[28] Bourrat X.: Electrically conductive grades of carbon black structure and properties. Carbon, 31, 287-302 (1993). DOI: 10.1016/0008-6223(93)90034-8

[29] Zhang W., Dehghani-Sanij A. A., Blackburn R.: Carbon based conductive polymer composites. Journal of Materials Science, 42, 3408-3418 (2007). DOI: $10.1007 / \mathrm{s} 10853-007-1688-5$

[30] Kagjiya T., Nishimoto S., Watanabe Y., Kato M.: Importance of the amorphous fraction of polypropylene in the resistance of radiation-induced oxidative degradation. Polymer Degradation and Stability, 12, 261-275 (1985).

DOI: $10.1016 / 0141-3910(85) 90094-1$

[31] El-Zaher N. A., Micheal M. N.: Time optimization of UV-ozone pretreatment for improving wool fabrics properties. Journal of Applied Polymer Science, 85, 1469-1476 (2002). DOI: 10.1002/app.10750

[32] Biscoe J., Warren B. E.: An X-ray study of carbon black. Journal of Applied Physics, 13, 364-371 (1942).

DOI: $\underline{10.1063 / 1.1714879}$

[33] Ungár T., Gubicza J., Tichy G., Pantea C., Zerda T. W.: Size and shape of crystallites and internal stresses in carbon black. Composites Part A: Applied Science and Manufacturing, 36, 431-436 (2005). DOI: $10.1016 /$ j.compositesa.2004.10.017 